\title{
A NEW GENUS OF THE TRIBE MESOSTENINI FROM CHILE (HYMENOPTERA, ICHNEUMONIDAE)*
}

\author{
By Charles C. Porter \\ Biological Laboratories, Harvard University
}

In my work on the Chilean Mesostenini it early became evident that the Cryptus cyanipennis of Brulle, one of the most striking and easily recognizable of the described mesostenines of temperate South America, is sufficiently distinct from other known forms to deserve separate generic status. I therefore give below a description of this new genus together with a brief discussion of its affinities and a redescription of the type species.

\section{Xiphonychidion, new genus}

Head transverse, temples strongly receding behind the eyes. Frons unarmed. Face gently convex between insertion of antennae and clypeus. Clypeus strongly convex, bluntly pyramidal in profile, the apical margin truncate, without a tooth. Antennae subequal to body in length, not at all thickened medially, subapical part of female antennae scarcely flattened below, white-annulate well beyond middle in both sexes. Epomia strong, with a little swelling above. Mesoscutum broadly convex, mat, with gross transverse foveolations arranged in roughly longitudinal series between which are much more finely sculptured areas; notaulus obsolete, not extending far beyond middle of mesoscutum, most clearly defined basally where it is a broad foveolate depression. Scutellum low, gently convex. Propodeum grossly and rather regularly rugoso-reticulate throughout, basal trans-carina complete; areola rather weakly to quite strongly delimited, smallish; apical trans-carina obsolete except medially, where it borders areola behind, forming very strong, blunt sublateral crests; spiracle long-elliptical. Wings dark-infumate with purplish reflections. Areolet very large, pentagonal, a little higher than wide, intercubiti straight, almost parallel, very slightly converging above; ramellus long and well-developed; nervulus postfurcal by about $\mathrm{I} / 3$ its length; median part of mediella straight; nervellus broken at about its lower $\mathrm{I} / 3$ in female, a little below middle in male; axillus far from anal margin of hind wing but distinctly closer to it than to submediella over most of its length. First abdominal segment rather slender; postpetiole moderately expanded, part behind spiracles about $\mathrm{I} . \mathrm{O}$ times as long as wide

*Manuscript received by the editor December 20, 1962. 
in female and about I.I times as long as wide in male; spiracles well behind middle; a strong, bluntly-triangular lateral expansion subbasally; ventro-lateral carinae strong throughout; dorso-lateral carinae rather weak basad of spiracles; median dorsal carinae distinct from a little before to well beyond spiracles. Second tergite shining, with numerous minute setiferous punctures, emitting rather long, moderately-dense hairs. Succeeding tergites with rather long, thick, black, appressed hairs over most of their surface, giving a generally dull, velvety sheen at low magnification. Ovipositor about 0.4 times as long as the fore-wing, somewhat depressed above preapically, without a nodus, strikingly hooked downward at tip, the tips of the lower valves not at all enclosing the upper valve.

Type species: Cryptus cyanipennis Brullé

\section{Xiphonychidion cyanipenne (Brullé), new combination}

Cryptus cyanipennis Brullé, 1846, Histoire naturelle des insectes hyménopterès. 4:188. female. Type, female. Chile: La Conception (lost).

Cryptus capensis Dalla Torre, 1902. Catalogus hymenopterorum 3: 564. Lapsus for cyanipennis.

Female: length of fore-wing $14-17 \mathrm{~mm}$. Ovipositor 0.4 times as long as fore-wing.

First flagellar segment about 5.6 times as long as wide apically. Front with a few strong, somewhat irregular transverse wrinkles, smooth and shining below, becoming mat above. Prepectal carina strong, reaching or almost reaching subalarum. Metapleurum grossly rugulose. Hind femur about 4.7 times as long as deep at middle. Postpetiole smooth and shining with moderately dense, minute setiferous punctures and a shallow, anteromedian depression.

Dull black, the following more or less well-developed white marks: rather narrow post-median annulus on flagellum, frontal orbits narrowly, elongate spot at top of eye, narrow line on posterior orbit, spot at bottom of eye, and hind tarsomeres 3-4 (sometimes also base of 2). Wings deeply infumate, with purplish reflections.

Male: length of fore-wing about $12.5 \mathrm{~mm}$. First flagellar segment approximately 3.4 times as long as wide apically.

Colored as in female.

Specimens examined: Five females and one male: Concepción, Chile, I 903 and 1904, P. Herbst. One female: Valparaiso, Chile, 2.XI, 1919, P. Herbst. One male: Penco, Chile, I.I908, P. Herbst. All in collection of Museum of Comparative Zoölogy at Harvard University. 
Xiphonychidion is a member of the Trachysphyrus Group of the subtribe Mesostenina of the tribe Mesostenini. Because of its large areolet, elongate propodeal spiracle, and almost straight mediella $X$. cyanipenne may be accounted a typical representative of this series of genera. From all described species, however, it differs conspicuously in the peculiar hooked-down ovipositor tip which indicates, perhaps, some rather special host. Otherwise, its closest approach is probably to Trachysphyrus Haliday to the vicinity of which it will run in Townes' key to the Nearctic genera (1962, Bull. U. S. Nat. Mus. 216, Pt. 3), differing, however, in its strongly convex clypeus, obsolete notauli, postfurcal nervulus, and in the prominent sub-basal triangular projection of the first abdominal segment.

The generic name is derived from the Greek xiphos - sword, onyx (onychos) - claw, and idion, a diminutive suffix. It refers to the characteristic ovipositor tip.

In conclusion I wish to express my thanks to Dr. H. K. Townes of the University of Michigan whose encouragement and vast knowledge are a constant help to me in my work on the South American Mesostenini. The synonomy given in this paper was kindly supplied by Dr. Townes from the manuscript of his projected Catalogue and Reclassification of the Neotropical Ichneumonidae. 

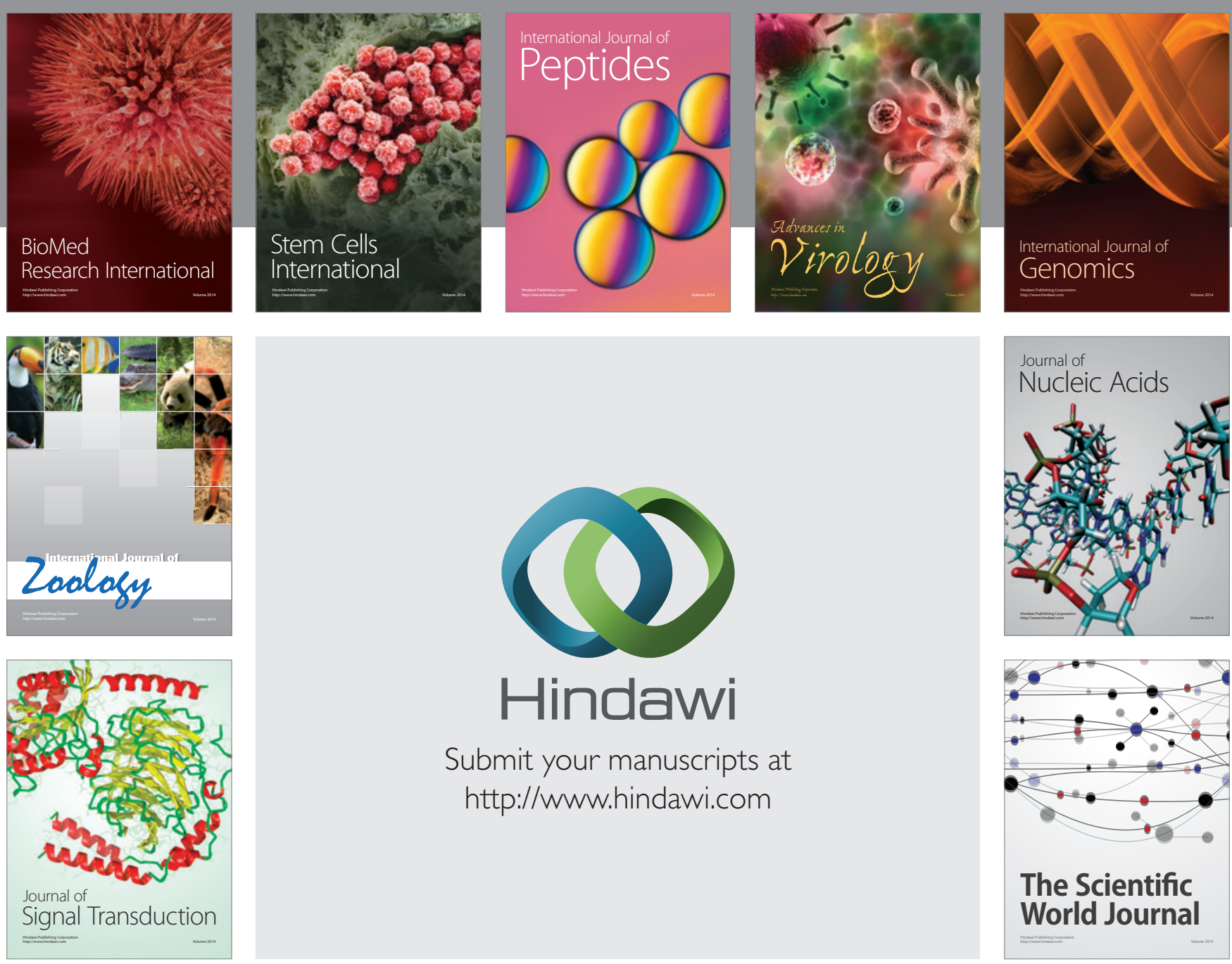

Submit your manuscripts at

http://www.hindawi.com
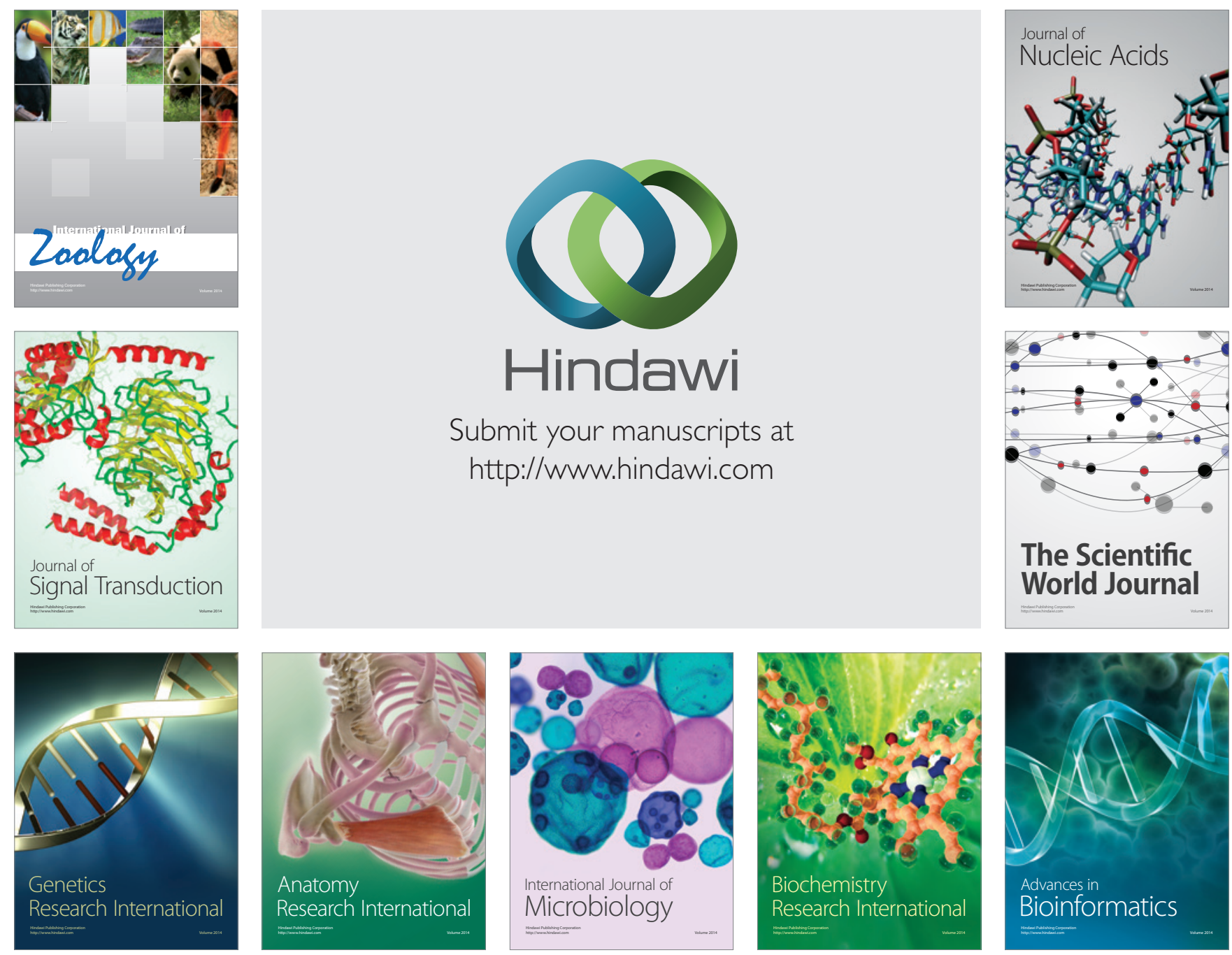

The Scientific World Journal
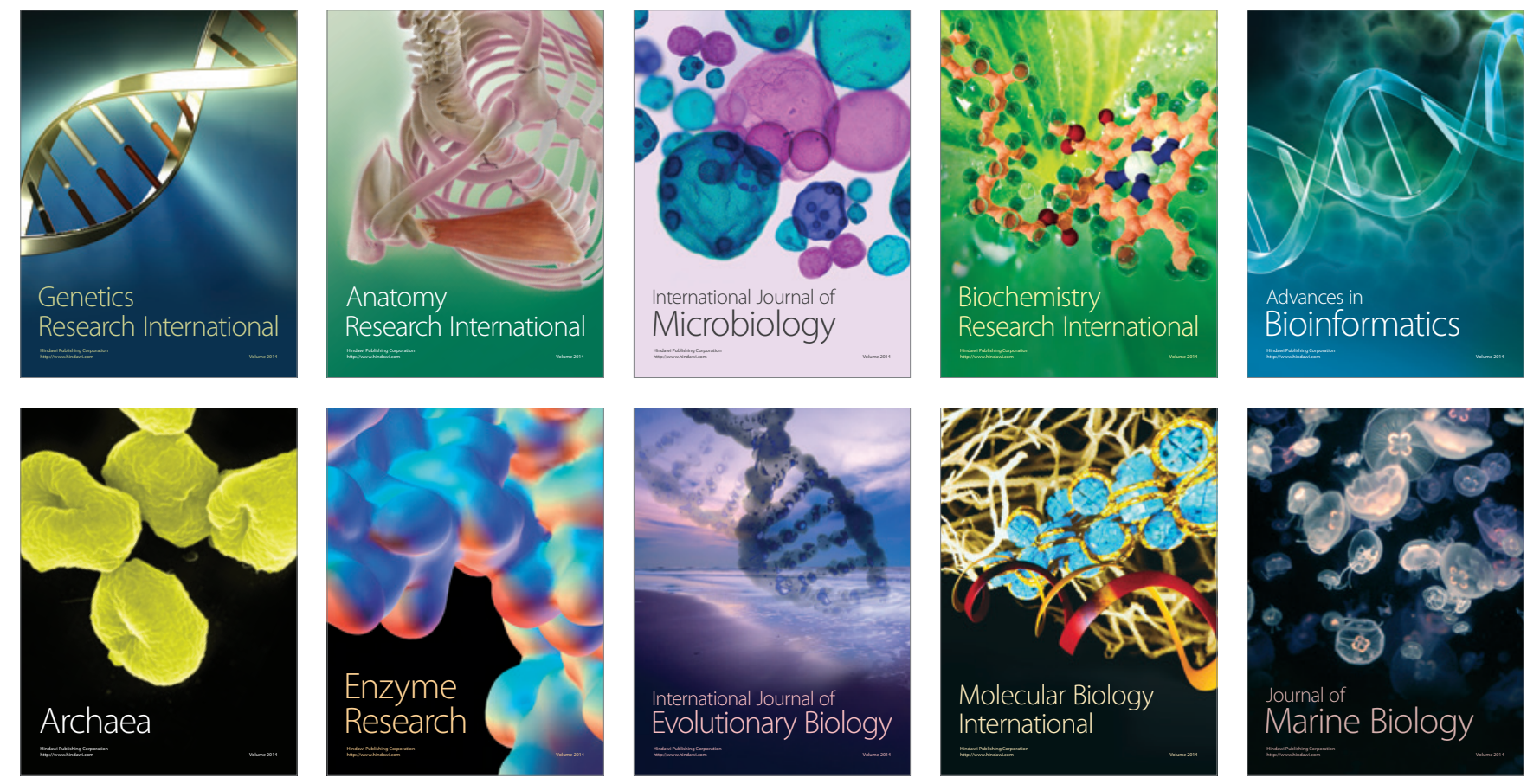